\title{
$\infty \sqrt{1}$ Stroke and \\ No benefit of flat head positioning in early moderate-severe acute ischaemic stroke: a HeadPoST study subgroup analysis
}

To cite: Brunser AM, Ouyang $M$, Arima $\mathrm{H}$, et al. No benefit of flat head positioning in early moderate-severe acute ischaemic stroke: a HeadPoST study subgroup analysis. Stroke \& Vascular Neurology 2020;5: e000387. doi:10.1136/svn2020-000387

- Additional material is published online only. To view please visit the journal online (http://dx.doi.org/10.1136/svn2020-000387).

Received 27 March 2020 Revised 20 May 2020

Accepted 28 May 2020 Published Online First 25 June 2020

\section{Check for updates}

(C) Author(s) (or their employer(s)) 2020. Re-use permitted under CC BY-NC. No commercial re-use. See rights and permissions. Published by BMJ.

For numbered affiliations see end of article.

Correspondence to Dr Alejandro M Brunser; abrunser2017@gmail.com

Alejandro M Brunser (D) ,1,2 Menglu Ouyang, ${ }^{3,4}$ Hisatomi Arima, ${ }^{5}$ Pablo M Lavados, ${ }^{2}$ Thompson Robinson, ${ }^{6}$ Paula Muñoz-Venturelli, ${ }^{2,3}$ Verónica V Olavarría (1) , Laurent Billot, ${ }^{3}$ Marre L Hackett, ${ }^{3,7}$ Lili Song, ${ }^{3,4}$ Sandy Middleton, ${ }^{8}$ Octavio Pontes-Neto, ${ }^{9}$ Tsong-Hai Lee, ${ }^{10}$ Caroline Watkins, ${ }^{7}$ Craig S Anderson ${ }^{3,4}$

\section{ABSTRACT}

Background Although the Head Positioning in acute Stroke Trial (HeadPoST) showed no effect of the flat head position (FP; vs sitting up head position (SUP)) on functional outcome, we hypothesised that it could still offer benefits if commenced early in those with acute ischaemic stroke (AIS) of at least moderate severity.

Methods Subgroup analysis of HeadPoST in participants with National Institutes of Health Stroke Scale (NIHSS) scores $\geq 7, \geq 10$ and $\geq 14$, randomised to FP or SUP $<4.5$ hours of AIS onset on functional outcomes defined by a shift in scores on the modified Rankin scale (mRS) and death/disability (mRS scores 3-6), and any cardiovascular serious adverse event. Logistic regression analyses were undertaken adjusted for study design and baseline risk factors.

Results There was no significant differential treatment effect in patient subgroups defined by increasing baseline NIHSS scores: adjusted $\mathrm{OR}$ and $95 \% \mathrm{Cl}$ for ordinal shift and binary (3-6) mRS scores: for NIHSS $\geq 7(n=867) 0.92(0.67$ to 1.25 ) and 0.74 (0.52 to 1.04$) ; \mathrm{NIHSS} \geq 10(n=606) 0.80$ ( 0.58 to 1.10$)$ and 0.77 (0.49 to 1.19$) ;$ NIHSS $\geq 14(n=378)$ 0.82 (0.54 to 1.24) and 1.22 (0.69 to 2.14).

Conclusions Early FP had no significant effect in patients with moderate-severe AIS.

Trial registration number NCT02162017.

Small non-randomised studies $^{12}$ indicate that patients with acute ischaemic stroke (AIS) who are positioned lying flat (FP) have increased mean cerebral blood flow velocity $(\mathrm{CBFV})$ in the middle cerebral artery (MCA), as measured by transcranial Doppler (TCD). Whether this physiological association translates into improved clinical outcome has been hotly debated. The Head Positioning in Stroke Trial (HeadPoST) mechanistic pilot study ${ }^{3}$ confirmed an increased $\mathrm{CBFV}$ in the ipsilateral MCA (primary outcome), but without any benefit on 90-day functional outcome, which was further confirmed in the main HeadPoST ${ }^{4}$ study undertaken in over 10000 patients who were evaluated using an international pragmatic cluster cross-over design. The later study has been criticised for including a broad range of patients, many with mild deficits, who were randomised within a long time window from symptom onset, as well as for including patients with primary intracerebral haemorrhage. ${ }^{5}$ Herein, we present post-hoc analyses specifically in the subgroup of patients with AIS with moderatesevere neurological impairment, defined by National Institutes of Health Stroke Scale (NIHSS) scores $\geq 7$, who commenced the head positioning intervention early after the onset of symptoms.

\section{METHODS}

HeadPoST main was an international, multicentre, cluster-randomised, cross-over, openlabel trial with blinded outcome evaluation in 11093 adults (age $\geq 18$ years) with AIS or intracranial hemorrhage (ICH) of flat head position $\left(0^{\circ}\right)$ compared with sitting up $\left(\geq 30^{\circ}\right.$, SP) head positioning, applied <24hours of admission at 114 hospitals in 9 countries during 2016-2017. The protocol is described in detail elsewhere, was approved by all ethics committees at each participating centre and involved informed consent obtained from patients or their approved surrogates. ${ }^{4}$ This study pertains to participants with AIS randomised $<4.5$ hours with baseline high NIHSS scores, grouped as $<7, \geq 7, \geq 10$ and $\geq 14$. Clinical outcomes were a shift in scores on the modified Rankin scale (mRS), death or disability (mRS 3-6) and any serious cardiovascular adverse event (SAE) including stroke, cardiac or other vascular events within 90 days post randomisation. We further analysed the treatment effect by subgroups with or without large vessel occlusion (LVO) in each stratum of NIHSS score. The presence 
of LVO was defined as an occlusion of MCA segments M1 or M2, terminal internal carotid artery, A1 segment of the anterior cerebral artery, $\mathrm{P} 1$ segment of the posterior cerebral artery or vertebral/basilar arteries on CT/MR angiography, digital subtraction, or by TCD.

Baseline characteristics and relevant hospital care were analysed with the $\chi^{2}$ test for categorical variables, t-test for normally distributed and Wilcoxon rank sum test for skewed distribution, as appropriate. Treatment effects were analysed by ordinal logistic regression, with a hierarchical mixed model and adjustment for study design (fixed intervention effect, fixed period effect, random cluster effect and effect of the interaction between random cluster and period). Subsequent models were adjusted for baseline confounders of age, sex, region, premorbid functional grade on the mRS, history of heart disease, diabetes mellitus, or stroke, and NIHSS score, with a forward approach. Results are presented as OR and $95 \%$ CIs. A standard two-sided level $\mathrm{p}<0.05$ was considered significant. All analyses were performed with SAS software V.9.4 (SAS Institute).

\section{RESULTS}

Online supplementary figure 1 shows the flow of patients flow according to NIHSS score subgroups. Table 1 shows the baseline demographic and clinical characteristics of 867 patients with NIHSS $\geq 7$, which were comparable between randomised groups. Similarly, there were no significant baseline differences in patient groups of NIHSS $<7 \quad(n=950), \geq 10 \quad(n=606)$ or $\geq 14 \quad(n=378$; online supplemental appendix, tables S1-3, respectively). At

Table 1 Baseline characteristics of patients who commenced head positioning within 4.5 hours of acute ischaemic stroke onset with initial National Institute of Health Stroke Scale (NIHSS) score $\geq 7$

\begin{tabular}{|c|c|c|c|}
\hline Baseline characteristics & $\begin{array}{l}\text { Lying flat } \\
\mathrm{N}=432\end{array}$ & $\begin{array}{l}\text { Sitting up } \\
\mathbf{N}=435\end{array}$ & P value \\
\hline Age (years) & $73.1(13.3)$ & $72.3(13.5)$ & 0.35 \\
\hline Region, n (\%) & & & 0.08 \\
\hline Australia and UK & $294(68.1)$ & $272(62.5)$ & \\
\hline South America & $34(7.9)$ & $49(11.3)$ & \\
\hline Hypertension, n (\%) & $288(67.1)$ & $265(60.9)$ & 0.06 \\
\hline Previous stroke, n (\%) & $89(20.6)$ & $103(23.7)$ & 0.28 \\
\hline Atrial fibrillation, n (\%) & $95(22.2)$ & $94(21.8)$ & 0.86 \\
\hline Aspirin use, n (\%) & $141(32.7)$ & $154(35.4)$ & 0.40 \\
\hline Anticoagulant use, n (\%) & 53 (12.3) & 47 (10.9) & 0.50 \\
\hline AIS category, n (\%) & & & 0.58 \\
\hline Large vessel & $133(30.8)$ & $134(30.8)$ & \\
\hline Cardioembolic & $110(25.5)$ & $101(23.2)$ & \\
\hline Lacunar & $59(13.7)$ & $52(12.0)$ & \\
\hline Other & $130(30.1)$ & $148(34.0)$ & \\
\hline NIHSS at admission & $13.0(9.0$ to 18.0$)$ & $12.0(9.0$ to 18.0$)$ & 0.34 \\
\hline 5 (severe disability) & $2(0.5)$ & $6(1.4)$ & \\
\hline
\end{tabular}

Data are $\mathrm{n}(\%)$, mean (SD) and median (IQR).

AIS, acute ischaemic stroke; mRS, modified Rankin scale. 
Table 2 90-day outcomes by baseline neurological severity

\begin{tabular}{|c|c|c|c|c|c|}
\hline Outcome* & Lying flat versus sitting up & OR $(95 \% \mathrm{Cl})$ & $P$ value & aOR $(95 \% \mathrm{Cl})$ & P value \\
\hline \multicolumn{6}{|l|}{ NIHSS $<7$} \\
\hline Ordinal mRS & & 1.07 (0.83 to 1.37$)$ & 0.62 & $1.03(0.80$ to 1.33$)$ & 0.73 \\
\hline Death & $3.9 \%$ versus $3.2 \%$ & $1.31(0.65$ to 2.66$)$ & 0.46 & Did not converge† & \\
\hline Cardiovascular SAEs* & $7.3 \%$ versus $7.2 \%$ & 1.03 (0.62 to 1.72$)$ & 0.90 & $1.05(0.62$ to 1.78$)$ & 0.85 \\
\hline Ordinal $\mathrm{mRS}$ & & $0.94(0.71$ to 1.26$)$ & 0.69 & $0.92(0.67$ to 1.25$) \ddagger$ & 0.59 \\
\hline Binary mRS 3-6 & $58.7 \%$ versus $62.2 \%$ & $0.86(0.67$ to 1.15$)$ & 0.31 & $0.74(0.52$ to 1.04$)$ & 0.08 \\
\hline Death & $13.6 \%$ versus $15.4 \%$ & 0.91 (0.59 to 1.41$)$ & 0.67 & $0.80(0.51$ to 1.27$)$ & 0.34 \\
\hline Cardiovascular SAEs* & $16.0 \%$ versus $12.2 \%$ & $1.31(0.87$ to 1.99$)$ & 0.20 & $1.21(0.79$ to 1.86$)$ & 0.37 \\
\hline \multicolumn{6}{|l|}{ NIHSS $\geq 10$} \\
\hline Death & $17.2 \%$ versus $20.5 \%$ & 0.85 (0.52 to 1.38$)$ & 0.50 & $0.76(0.46$ to 1.24$)$ & 0.27 \\
\hline Cardiovascular SAEs* & $17.9 \%$ versus $15.4 \%$ & $1.16(0.73$ to 1.83$)$ & 0.54 & $1.06(0.66$ to 1.70$)$ & 0.81 \\
\hline \multicolumn{6}{|l|}{ NIHSS $\geq 14$} \\
\hline Ordinal mRS & & 0.83 (0.56 to 1.27$)$ & 0.36 & $0.82(0.54$ to 1.24$)$ & 0.34 \\
\hline Binary mRS 3-6 & $77.3 \%$ versus $75.0 \%$ & $1.13(0.65$ to 1.98$)$ & 0.66 & 1.05 (0.54 to 2.01$)$ & 0.89 \\
\hline Death & $22.8 \%$ versus $27.8 \%$ & 0.70 (0.42 to 1.19$)$ & 0.19 & $0.72(0.40$ to 1.30$)$ & 0.28 \\
\hline Cardiovascular SAEs* & $23.5 \%$ versus $18.1 \%$ & $1.29(0.75$ to 2.21$)$ & 0.36 & $1.30(0.73$ to 2.31$)$ & 0.38 \\
\hline
\end{tabular}

Adjusted OR (aOR) obtained for further adjusted age, sex, region groups, premorbid grade (0-1 vs 2-5) according to modified Rankin scale (mRS) assessed at baseline, comorbidity of heart disease, stroke or diabetes mellitus and National Institutes of Health Stroke Scale (NIHSS) at baseline as continuous variable.

${ }^{*}$ Cardiovascular serious adverse events (SAEs) include cerebrovascular events, cardiac events or other vascular events. †Hierarchical model cannot be converge due to very few cases of death in this subgroup.

†Hierarchical model only adjusted study design, age, sex, region groups, premorbid grade (0-1 vs 2-5) according to mRS assessed at baseline and comorbidity of heart disease, stroke or diabetes mellitus.

90 days post randomisation, there was no significant difference in functional recovery by ordinal mRS (adjusted OR (aOR) $0.92,95 \%$ CI 0.67 to 1.25 ), binary mRS scores 3-6 (aOR $0.74,95 \%$ CI 0.52 to 1.04 ) or any cardiovascular SAE (aOR $1.21,95 \%$ CI 0.79 to 1.86 , table 2 ) in NIHSS $\geq 7$ group. Likewise, there were no significant differences in the treatment effects on these outcomes in patients with NIHSS scores $<7, \geq 10$ and $\geq 14$ (table 2; online supplementary figure 2). The probability of a good outcome was significantly greater in the patients with $\mathrm{LVO}$ and an NIHSS $<7$ ( $p=0.005$ for interaction).

\section{DISCUSSION}

In these post-hoc analyses of participants in the HeadPoST study with more severe neurological deficit, there was no differential effect of randomised head positioning commenced early after onset of symptoms on functional outcomes or cardiovascular SAE. These patients had a high likelihood of a large ischaemic penumbra, based on an early time window after symptom onset ${ }^{6}$ and high probability of underlying LVO by virtue of an initial NIHSS score $\geq 7{ }^{7}$ Although we cannot exclude the possibility of missing a more modest effect from low statistical power in subgroups or of poor fidelity of the intervention, these results provide further confirmation that any change in MCA CBFV from the FP does not appear to translate into improved clinical outcomes as compared with SP in patients with severe AIS.

We have previously shown that in the FP group, $14 \%$ more patients had an increase of CBFV of $\geq 8 \mathrm{~cm} / \mathrm{s}$ over 24 hours in the ipsilateral MCA when compared with SP after AIS. ${ }^{3}$ While this increase in CBFV could influence NIHSS score improvement after AIS, ${ }^{1}$ this may not necessarily influence overall recovery at 90 days, ${ }^{34}$ as such change in CBFV represents only an increase of $13 \%-17 \%$ of the flow velocity of a normal artery. ${ }^{8}$ It is unknown if such a modest increase in flow velocity is able to maintain viable penumbra over a longer period of time, even up to 24 hours. ${ }^{9}$ TCD evaluations of acute MCA occlusions in AIS are usually scored on the Thrombolysis in Brain Ischaemia (TIBI) scale (from 0 being occluded to 5 representing normal flow velocity), and have shown that a change in ultrasonographic flow patterns from a TIBI signal of $0-3$ to $4-5$ is associated with good functional outcome. These changes in TIBI scores represent a minimum threefold increase in flow 
velocity of an affected artery (change from TIBI 3-5). ${ }^{10}$ Thus, it is unlikely that an increase of $13 \%$ in flow velocity in $14 \%$ of patients, who were assigned to FP, could have had a significant effect on overall recovery. Moreover, no study has shown that changes in CBFV equate to improvements in the ischaemic penumbra. ${ }^{9}$ Even within patients with AIS with the highest NIHSS scores $(\geq 10$ and $\geq 14),{ }^{7911}$ we could not detect a treatment effect. Nevertheless, we did find a significant interaction between LVO and low NIHSS, favouring FP, which could indicate that these patients have good collaterals from mild clinical manifestations. The findings could also be due to chance in only 42 patients randomised to FP.

One explanation for our neutral results in patients with high NIHSS scores is that FP has no effect if there is no collateral blood flow, even in the very early stages of AIS. ${ }^{6}$ It is possible that FP could still have some effect in highly selected patients, such as those with LVO and very competent collaterals, or those with incomplete reperfusion from lysis or mechanical thrombectomy therapies, but this will be challenging to prove in a randomised trial.

An important caveat is that while our study included a very large number of randomised patients who had severe strokes, only a small proportion had imaging confirmation of the location and extent of vessel occlusion. Moreover, these are post-hoc analyses of subgroups and thus prone to bias and random effects.

In summary, the use of FP of patients early after the onset of moderate-severe AIS was not associated with functional recovery, but could be effective in patients with low NIHSS and LVO.

\section{Author affiliations}

${ }^{1}$ Department of General Emergency, Clínica Alemana de Santiago, Clínica Alemana Universidad del Desarrollo, Santiago, Chile

${ }^{2}$ Department of Neurology and Psychiatry, Clínica Alemana de Santiago, Faculty of Medicine, Clínica Alemana Universidad del Desarrollo, Santiago, Chile

${ }^{3}$ The George Institute for Global Health, University of New South Wales, Sidney, New South Wales, Australia

${ }^{4}$ The George Institute in China, Peking University Health Science Center, Beijing, China

${ }^{5}$ Department of Preventive Medicine and Public Health, Fukuoka University,

Fukuoka, Japan

${ }^{6}$ Department of Cardiovascular Sciences and NIHR Leicester Biomedical Research Centre, University of Leicester, Leicester, United Kingdom

${ }^{7}$ Faculty of Health and Wellbeing, University of Central Lancashire, Preston, Lancashire, United Kingdom

${ }^{8}$ Nursing Research Institute, St Vincent's Health Network Sydney Australia, Australian Catholic University, Sydney, New South Wales, Australia

${ }^{9}$ Stroke Service-Neurology Division, Department of Neuroscience and Behavioral Sciences, Ribeirão Preto Medical School, University of Sao Paulo, Sao Paulo, Brazil

${ }^{10}$ Stroke Center and Department of Neurology, Linkou Chang Gung Memorial Hospital and College of Medicine, Chang Gung University, Taoyuan, Taiwan
Contributors AMB and M0: design substudy. LB: did the statistical analysis. All authors participated in their local centres for patients recruitment, and review this manuscript.

Funding The authors have not declared a specific grant for this research from any funding agency in the public, commercial or not-for-profit sectors.

Competing interests $A B$ reports research grants from Clínica Alemana de Santiago. PML reports research grants from The George Institute, Clínica Alemana de Santiago, and the Chilean Government, personal fees from Bristol Meyer Squibb AstraZeneca and Bayer, and an unrestricted research grant from Lundbeck. TR is a National Institutes for Health Research Senior Investigator. WV reports research grants from Clínica Alemana de Santiago, Boehringer-Ingelheim and Conicyt. PM-V reports research grants from Clínica Alemana de Santiago. MLH holds a National Health and Medical Research Council (NHMRC) of Australia Career Development Fellowship. SM is a member of the NHMRC Research Committee in 2015-2018. OP-N reports research grants for the Brazilian Stroke Research Network from the Brazilian government. CSA holds an NHMRC Senior Principal Research Fellowship, and reports honoraria and travel reimbursement from Takeda, Boehringer Ingelheim and Amgen.

Patient consent for publication Not required.

Provenance and peer review Not commissioned; externally peer reviewed.

Open access This is an open access article distributed in accordance with the Creative Commons Attribution Non Commercial (CC BY-NC 4.0) license, which permits others to distribute, remix, adapt, build upon this work non-commercially, and license their derivative works on different terms, provided the original work is properly cited, appropriate credit is given, any changes made indicated, and the use is non-commercial. See: http://creativecommons.org/licenses/by-nc/4.0/.

\section{ORCID iDs}

Alejandro M Brunser http://orcid.org/0000-0002-8376-9450

Verónica V Olavarría http://orcid.org/0000-0003-4300-9921

\section{REFERENCES}

1 Wojner-Alexander AW, Garami Z, Chernyshev OY, et al. Heads down: flat positioning improves blood flow velocity in acute ischemic stroke. Neurology 2005;64:1354-7.

2 Schwarz S, Georgiadis D, Aschoff A, et al. Effects of body position on intracranial pressure and cerebral perfusion in patients with large hemispheric stroke. Stroke 2002;33:497-501.

3 Olavarría VV, Lavados PM, Muñoz-Venturelli P, et al. Flat-head positioning increases cerebral blood flow in anterior circulation acute ischemic stroke. A cluster randomized phase llb trial. Int J Stroke 2018;13:600-11.

4 Anderson CS, Arima H, Lavados P, et al. Cluster randomized, crossover trial of head positioning in acute stroke. N Engl J Med 2017;376:2437-47

5 Alexandrov AW, Tsivgoulis G, Hill MD, et al. HeadPoST: rightly positioned, or flat out wrong? Neurology 2018;90:885-9.

6 Powers WJ, Rabinstein AA, Ackerson T, et al. 2018 guidelines for the early management of patients with acute ischemic stroke: a guideline for healthcare professionals from the American heart Association/ American stroke association. Stroke 2018;49:e46-110.

7 Olavarría VV, Delgado I, Hoppe A, et al. Validity of the NIHSS in predicting arterial occlusion in cerebral infarction is time-dependent. Neurology 2011;76:62-8.

8 Hennerici M, Rautenberg W, Sitzer G, et al. Transcranial Doppler ultrasound for the assessment of intracranial arterial flow velocity-Part 1. Examination technique and normal values. Surg Neurol 1987;27:439-48.

9 Markus R, Reutens DC, Kazui S, et al. Hypoxic tissue in ischaemic stroke: persistence and clinical consequences of spontaneous survival. Brain 2004;127:1427-36.

10 Demchuk AM, Burgin WS, Christou I, et al. Thrombolysis in brain ischemia (TIBI) transcranial Doppler flow grades predict clinical severity, early recovery, and mortality in patients treated with intravenous tissue plasminogen activator. Stroke 2001;32:89-93.

11 Fischer U, Arnold M, Nedeltchev K, et al. NIHSS score and arteriographic findings in acute ischemic stroke. Stroke 2005;36:2121-5. 